\title{
MAXENT MODELING THE CURRENT AND FUTURE DISTRIBUTION OF THE INVASIVE PEST, THE FALL ARMYWORM (SPODOPTERA FRUGIPERDA) (LEPIDOPTERA: NOCTUIDAE), UNDER CHANGING CLIMATIC CONDITIONS IN CHINA
}

\author{
CAI, P. M. ${ }^{1,2,3 \#^{*}}-$ MeNG, F. H. ${ }^{1 \#}-$ SONG, Y. Z. $.^{1,2^{*}}-$ MA, C. H. ${ }^{1}-$ PENG, Y. W. ${ }^{1}-$ WU, Q. F. ${ }^{1}-$ \\ LEI, S. Y. ${ }^{1}-$ HONG, Y. C. ${ }^{1}-$ HUO, D. ${ }^{1}-$ LI, L. ${ }^{1}$ \\ ${ }^{1}$ Department of Horticulture, College of Tea and Food Science, Wuyi University, Wuyishan \\ 354300, China \\ ${ }^{2}$ Biological Control Research Institute, College of Plant Protection, Fujian Agriculture and \\ Forestry University, Fuzhou 350002, China
}

\author{
${ }^{3}$ Key Laboratory of Biopesticide and Chemical Biology, Ministry of Education, Fuzhou 350002, \\ China \\ ${ }^{\#}$ These two authors made equal contributions to this work. \\ ${ }^{*}$ Corresponding authors \\ e-mail: caipumo@qq.com; phone: +86-150-8045-6908 (Cai, P. M.); \\ e-mail:1023554932@qq.com; phone: +86-155-0690-0021 (Song, Y. Z.) \\ (Received $4^{\text {th }}$ Jun 2021; accepted $4^{\text {th }}$ Sep 2021)
}

\begin{abstract}
In this study we investigated the effects of climate change on the fall armyworm, Spodoptera frugiperda (Lepidoptera: Noctuidae). Based on the current distribution records of S. frugiperda and selected bioclimatic factors, we modelled its potential habitat suitability in China under four climate change scenarios using Maximum Entropy Models (MaxEnt) and Geographic Information Systems (GIS). Our results showed that: (1) the mean area under curve (AUC) values of both our initial and final models were greater than 0.978 , indicating high accuracy in the predictions; (2) the dominant environmental factors regulating the habitat suitability of S. frugiperda were Precipitation of Warmest Quarter (bio18), Temperature Seasonality (bio4), Annual Mean Temperature (bio1) and Precipitation Seasonality (bio15); (3) the highly suitable areas for S. frugiperda were mainly distributed in Jiangsu, Anhui, Jiangxi, most parts of Henan and Guangxi, central and eastern Hubei, central and southern Shaanxi, and southeastern and northern Zhejiang, accounting for $17.6 \%$ of China's landmass; (4) from the present until the 2070s, the areas of the non-suitable regions will decrease as climate warming becomes more severe, and the geometric center of the highly and total suitable areas will displace to the north under all four climate change scenarios. Keywords: biological invasion, Maximum Entropy Models, climate change, bioclimatic variables, habitat suitability
\end{abstract}

\section{Introduction}

Invasive species threaten ecosystems due to their impacts on native flora and fauna through predation and competition. They also threaten human-managed systems, such as those associated with agriculture, forestry and animal health (Simberloff et al., 2003). A considerable amount of evidence has indicated that their impact on new communities and ecosystems will be aggravated as a result of climate change (Ekesi et al., 2016), which is in itself one of the greatest threats to the global economy, agricultural production, animal health and biodiversity (Roy et al., 2011). Climate change will likely influence almost all 
aspects of the life history traits and population dynamics of pests, including their growth and development, metabolic rate, survival, propagation, and distribution range (Battisti et al., 2005; Tobin et al., 2008; Faccoli, 2009). Due to the sensitivity of insects to climate conditions, global climate change has significantly broadened their distribution, enhanced generation and ecological adaptability variations, altered the structure, composition, function, and succession of insect communities within ecosystems, and subsequently influenced the interrelationship among pests, natural enemies and plants, resulting in outbreaks of some species (Kyrre et al., 2012; Celine et al., 2012). Therefore, being able to predict changes in their distribution as a result of climate change is an important baseline to prevent and manage the introduction and diffusion of invasive species. This, in turn, will provide a reference for risk assessments and integrated pest management (Massin et al., 2012).

Spodoptera frugiperda (J. E. Smith) (Lepidoptera: Noctuidae), commonly known as the fall armyworm (FAW), is a polyphagous moth pest that can feed on more than 350 host plant species, although it has a preference towards cultivated grasses such as rice, maize, cotton, sorghum and sugarcane (Montezano et al., 2018). Native to the tropical and subtropical areas of the Americas, S. frugiperda was not recorded elsewhere until 2015 (Wang et al., 2020). The literature indicates that $S$. frugiperda invaded Africa as a stowaway on a passenger flight via the agricultural trade and rapidly diffused to almost the whole of sub-Saharan Africa due to its prominent dispersal ability (Day et al., 2017). This resulted in a 20-50\% decrease in maize production in the absence of management measures (Nagoshi, 2019). Since its introduction and establishment in Africa in 2016, $S$. frugiperda quickly spread to most of the maize production areas, leading to estimated financial losses between USD 2.48 and 6.19 billion every year (Day et al., 2017). Indeed, $S$. frugiperda has now invaded approximately 100 countries throughout the world and continues to search for new ecological niches, where it threatens agricultural production systems and potentially causes food insecurity (Center for Agriculture and Bioscience International, 2016).

In China, S. frugiperda was first recorded in Yunnan Province at the end of 2018, and in 2019 caused an estimated economic loss of CNY 29 billion to maize industries (Zhang et al., 2020). By 31st August 2020, it had been documented in 27 provinces/municipalities, encompassing 1338 counties, with a total damage area of 3.68 million hectares (National Agro-Tech Axtension and Service Center, 2020). Thus, it is very important to understand how climate change impacts its geographic distribution, to enable better detection, early warning, quarantine inspection and control.

Projecting the potential spatial distribution of pests is an important research area within quantitative pest risk analysis ( $\mathrm{Li}$ et al., 2018). As statistical modeling has developed, ecological theories combined with geographic information system (GIS) technologies have been utilized to improve our ecological understanding, particularly for agricultural production and conservation biology (Brito et al., 2009). Species distribution models (SDMs), including the maximum entropy model (MaxEnt), Climex, GARP, DOMAIN and BIOCLIM, are important tools widely applied to determine the impacts of climate change (Zhu et al., 2013). Their main principle is to apply known occurrence data, related environmental factors and certain algorithms to evaluate the ecological demands and habitat suitability for a given species. They can then provide a projection of different spatial and temporal ranges in order to forecast future distribution patterns (Venette et al., 2010). The MaxEnt model is the most commonly used predictive tool for quantifying the future distributions of a species and has been widely applied in the areas of ecology, 
conservation, biosafety and species evolution since it emerged in 2004 (Elith et al., 2006). The merits of the MaxEnt model are its high simulation precision with a small sample size, short operation time, convenient use, stable prediction results, and the ease with which results can be interpreted ( $\mathrm{Li}$ et al., 2013). However, it inevitably has certain defects; for example, abiotic factors without biotic factors are considered in MaxEnt operation, and the forecast from this software only represents the greatest possibility of species distribution rather than 'real' distributions (Wang et al., 2017).

Due to the severe impacts caused by $S$. frugiperda, several attempts to understand its response to different climate change scenarios have been made (Valdez-Torres et al., 2012; Ramirez-Cabral et al., 2017; Wang et al., 2020; Liu et al., 2020). The biomechanical pathways of $S$. frugiperda invasion in maize fields were investigated by Valdez-Torres et al. (2012), while possible changes in habitat suitability in its native regions were estimated based on two global circulation models (GCM) and known occurrence records (RamirezCabral et al., 2017). More recently, many research teams assessed the responses of S. frugiperda to different climatic variables within an invaded area (Baloch et al., 2020; Cokola et al., 2020; Fan et al., 2020; Wang et al., 2020), while Liu et al. (2020) determined its response to land use under current and future climate conditions. Additionally, Zacarias (2020) explored the potential implications of climate change on its global geographical distribution, as well as the interaction with its main economically-important host plants. Overall, the abovementioned research suggests that the invasive potential of $S$. frugiperda is largely attributed to factors related to temperature, rainfall and land use, with an immense potential for invasion in Africa (Ramirez-Cabral et al., 2017; Early et al., 2018; Cokala et al., 2020; Liu et al., 2020; Fan et al., 2020), South America (RamirezCabral et al., 2017), central Asia (Baloch et al., 2020), and other areas of Asia such as China (Liu et al., 2020; Wang et al., 2020).

Due to the devastating impacts of $S$. frugiperda invasion on agricultural production, along with its excellent spread ability, projecting the potential distribution of this pest in relation to climate conditions and ascertaining the regulating factors are important tasks. They are particularly important in China, where diverse host plants of this pest are widely grown, and where this pest has already begun to proliferate. Such knowledge will be useful for developing strategies to prevent it from spreading and reduce the incidence of high-level infestations. In the present study, a MaxEnt model based on available occurrence data was chosen to estimate the distribution pattern and spread of $S$. frugiperda in China under different climate change scenarios. The main aims were as follows: (1) to confirm key climatic factors that restrict the potential distribution of S. frugiperda; (2) to forecast how its suitable habits will change under different emission scenarios; as well as (3) to provide a theoretical reference framework and data support for the comprehensive prevention and management of this pest in China.

\section{Materials and Methods}

\section{Species occurrence data}

Global presence records of $S$. frugiperda were compiled from three main sources: two online species distribution databases, the Global Biodiversity Information Facility (GBIF, https://www.gbif.org/) and the Centre for Agriculture and Bioscience International (CABI, https://www.cabi.org/), and a significant amount of published literature. Geographical coordinates for each data point were either referenced from information in the article or acquired from Google Earth. In strict conformity with the requirements of 
MaxEnt, adjacent records, duplicate records, and fuzzy records were eliminated (Jiang et al., 2018), and data were manually inspected for accuracy. Ultimately, 375 validated records were used to establish the models (Figure 1). All filtered occurrence records were imported into Microsoft Excel and saved as “.csv" files (Wang et al., 2019).

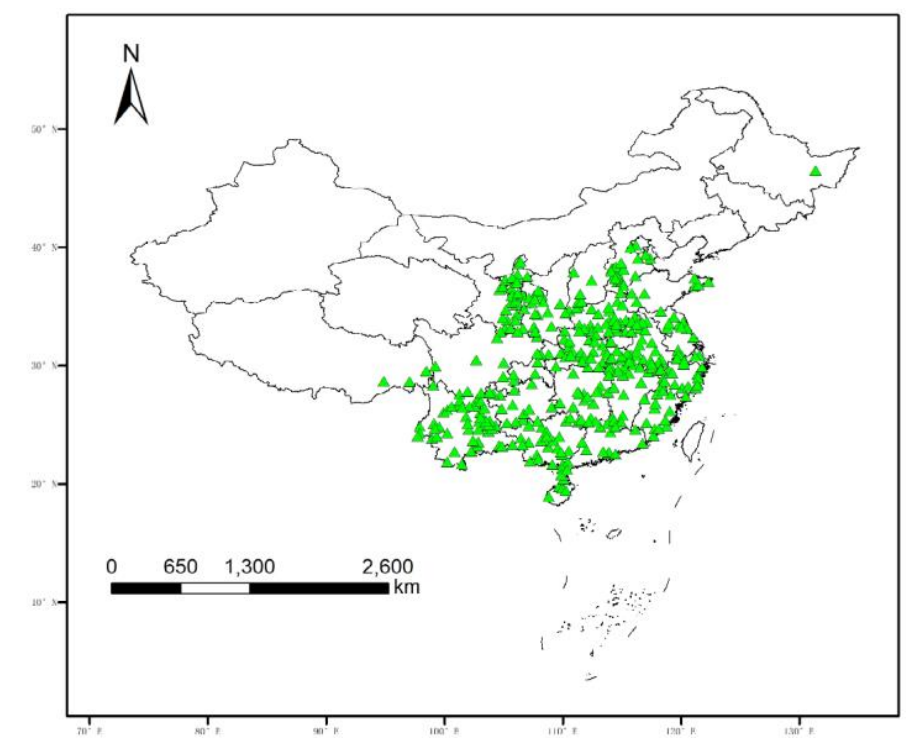

Figure 1. Geographic distribution of S. frugiperda occurrence in China

\section{Environmental variables}

To evaluate the climatic suitability regionalization of $S$. frugiperda in China, environmental variables that could characterize the ecological requirements of this pest were chosen as initial environmental factors. Data for 19 bioclimatic variables (Table 1) were downloaded from the WorldClim database (http://www.worldclim.org/) for current climatic conditions. These data included average, minimum and maximum ambient temperatures as well as precipitation values documented for the interval between 1950 and 2000. For assessing the impact of climate change on the future niche suitability of S. frugiperda, four representative $\mathrm{CO}_{2}$ concentration pathways (RCPs) issued by the Intergovernmental Panel on Climate Change (IPCC) were applied as future climate change scenarios, namely RCP2.6, RCP4.5, RCP6.0 and RCP8.5, which indicate different levels of greenhouse gas emission (Dong and Gao, 2014). The future time intervals in consideration were the 2050s (2041-2060) and 2070s (2061-2080); predicted future environmental data were also obtained from the WorldClim database. All bioclimatic variables under current and future conditions had a spatial resolution of 2.5 arcminutes (about $9 \mathrm{~km}$ at the equator).

\section{Environmental data for defining ecological niches}

The MaxEnt model (version 3.3.3) applies environmental data and species distribution data to predict future distributions under a maximum entropy scenario. It is open source and available from http://www.cs.princeton.edu/. MaxEnt is an ideal predictive tool for simulating the geographical distribution of species and has spectacular merits (Wang et al., 2019), thus was chosen for application in the present research. The specific operational procedures for MaxEnt are described below. 


$$
-4531 \text { - }
$$

Table 1. Environmental variables used to predict the distribution of S. frugiperda in China

\begin{tabular}{c|c|c}
\hline Code & Bioclimatic variable & Unit \\
\hline bio1 & Annual Mean Temperature & ${ }^{\circ} \mathrm{C}$ \\
bio2 & Mean Diurnal Range (Mean of monthly (max temp - min temp) ) & ${ }^{\circ} \mathrm{C}$ \\
bio3 & Isothermality (BIO2/BIO7) $(* 100)$ & - \\
bio4 & Temperature Seasonality (standard deviation *100) & - \\
bio5 & Max Temperature of Warmest Month & ${ }^{\circ} \mathrm{C}$ \\
bio6 & Min Temperature of Coldest Month & ${ }^{\circ} \mathrm{C}$ \\
bio7 & Temperature Annual Range (BIO5-BIO6) & ${ }^{\circ} \mathrm{C}$ \\
bio8 & Mean Temperature of Wettest Quarter & ${ }^{\circ} \mathrm{C}$ \\
bio9 & Mean Temperature of Driest Quarter & ${ }^{\circ} \mathrm{C}$ \\
bio10 & Mean Temperature of Warmest Quarter & ${ }^{\circ} \mathrm{C}$ \\
bio11 & Mean Temperature of Coldest Quarter & ${ }^{\circ} \mathrm{C}$ \\
bio12 & Annual Precipitation & $\mathrm{mm}$ \\
bio13 & Precipitation of Wettest Month & $\mathrm{mm}$ \\
bio14 & Precipitation of Driest Month & $\mathrm{mm}$ \\
bio15 & Precipitation Seasonality (Coefficient of Variation) & - \\
bio16 & Precipitation of Wettest Quarter & $\mathrm{mm}$ \\
bio17 & Precipitation of Driest Quarter & $\mathrm{mm}$ \\
bio18 & Precipitation of Warmest Quarter & $\mathrm{mm}$ \\
bio19 & Precipitation of Coldest Quarter & $\mathrm{mm}$ \\
\hline
\end{tabular}

Abbreviations: -, not applicable

To prevent collinearity between modeling variables influencing the prediction outcomes, the variables were screened in accordance with the following procedure (Wang et al., 2020). First, the initial model was created by importing the occurrence points of $S$. frugiperda and 19 bioclimatic variables into the MaxEnt software. Within the framework of the initial model, the 'Random test percentage' was set as 25, and 'Make pictures of predictions' and 'Do jackknife to determine factor importance' were selected; the other model values were set to default. Then, the percent contribution and permutation contribution of each variable to the initial simulation results were investigated by a Jackknife test to choose the main environmental factors for modeling. To avoid variable spatial autocorrelation, a Pearson correlation analysis was conducted on the filtered variables using SPSS v.22 (SPSS, Inc., Chicago, IL, USA). Based on the percent contribution of each variable in the initial model, bioclimatic variables with correlation coefficients $>|0.8|$ (highly correlated) were filtered. Only one variable from each of such pairs, chosen based upon its relative importance in modeling the $S$. frugiperda distribution and its predictive power (such as percent contribution and jackknife training gain) was chosen for developing the model (Wei et al., 2017). After this screening step, 7 bioclimatic variables were chosen as the potential predictors of $S$. frugiperda habitat suitability, namely Annual Mean Temperature (bio1), Mean Diurnal Range (bio2), Temperature Seasonality (bio4), Max Temperature of Warmest Month (bio5), Precipitation Seasonality (bio15), Precipitation of Warmest Quarter (bio18) and Precipitation of Coldest Quarter (bio19). 


$$
\text { - } 4532 \text { - }
$$

\section{Distribution modeling}

The 7 selected bioclimatic variables, along with occurrence records, were applied to construct the relationship between the potential distribution of S. frugiperda and current climate conditions. This was then further processed to project the potential distribution under future climate conditions (Fand et al., 2014). The occurrence points of S. frugiperda and the 7 bioclimatic variables were imported into the MaxEnt model to simulate the distribution of S. frugiperda in China. In our model, $25 \%$ of the distribution points were applied for testing the model and $75 \%$ of the points were used for training. Moreover, the response curve for each climatic variable was used to determine the relationship between the probability distribution and the variable, ranging from highest suitability (value of 0 ) to lowest suitability (value of 1) (Khanum et al., 2013). In the final model, "Random seed" was selected. Model replicates were run 10 times to enhance model performance, and the other model settings were the same as for the initial model. The best model with the highest AUC (Area Under Curve) value was chosen to evaluate the probability distribution (Xu et al., 2019).

The ASCII-formatted file output from the MaxEnt model was imported into ArcGIS and converted into a raster format file using "Conversion Tools", which was used to classify and visualize the distribution region, and the "Extraction" function was used to produce a graphical representation of the distribution across China. Jenks' natural breaks were employed to reclassify the distribution threshold and divide the levels of habitat suitability into four categories: unsuitable area (no risk, $\mathrm{P}<0.10$ ), marginally suitable area (low risk, $0.10<\mathrm{P}<0.31$ ), moderately suitable area (medium risk, $0.31<\mathrm{P}<0.52$ ) and highly suitable area (high risk, $\mathrm{P}>0.52$ ), which were then displayed as different colors (Wang et al., 2018, 2019).

\section{Model evaluation}

The receiver operating characteristic curve (ROC) is an effective and widely used tool for assessing the discriminative power of a species distribution model (Wang et al., 2020). The area under a ROC curve (AUC), theoretically varying from 0.5 to 1.0 , was taken as a measure of model accuracy, with a value close to 1 indicative of high simulation accuracy (Araujo et al., 2005). Specifically: for a value $0.5 \leq \mathrm{AUC}<0.5$, the assessment criteria suggest prediction failure (fail); $0.6 \leq \mathrm{AUC}<0.7$, poor prediction results (poor); $0.7 \leq \mathrm{AUC}<0.8$, generally fair prediction results (fair); $0.8 \leq \mathrm{AUC}<0.9$, good prediction results (good); and $0.9 \leq \mathrm{AUC}<1$, excellent prediction results (excellent) (Wang et al., 2020). For our model, the AUC values were generally found to be greater than 0.8 , suggesting that it is superior to the random model (Swets, 1988).

\section{Results}

\section{Screening of the main environmental variables}

Based on the principle of climate similarity, MaxEnt is a mathematical model that can be used to investigate the correlation between geographical distribution and environmental factors. Selection of climatic factors is the main determinant for the precision of the results. The percent contribution for each bioclimatic variable on the distribution simulation model was calculated by the knife cutting method (Table 2), revealing that Precipitation of Warmest Quarter (bio18) made the largest contribution to the predicted distribution of S. frugiperda (43.9\%), followed by Temperature Seasonality 


$$
-4533-
$$

(bio4), Annual Mean Temperature (bio1) and Precipitation Seasonality (bio15), with $21.1 \%, 15.6 \%$ and $11.6 \%$, respectively. Notably, the variables Mean Diurnal Range (bio2), Precipitation of Coldest Quarter (bio19) and Max Temperature of Warmest Month (bio5) only had slight effects at $5.2 \%, 1.8 \%$ and $0.8 \%$, respectively. Variables which did not show any contribution were removed from our model. Finally, a Pearson correlation coefficient analysis was used to confirm that the extracted variables had no co-correlation with each other (Table 3). On this basis, the final model of the habitat suitability of S. frugiperda in China was constructed, and the accuracy of the prediction results was assessed.

Table 2. Relative percentage of bioclimatic factors imported into MaxEnt to predict the current and future distribution of $S$. frugiperda

\begin{tabular}{c|c|c}
\hline Environmental variable & Percent contribution (\%) & Permutation importance (\%) \\
\hline Bio_18 & 43.9 & 7.1 \\
Bio_4 & 21.1 & 33.8 \\
Bio_1 & 15.6 & 39.2 \\
Bio_15 & 11.6 & 8.4 \\
Bio_2 & 5.2 & 7.0 \\
Bio_19 & 1.8 & 1.9 \\
Bio_5 & 0.8 & 2.5 \\
\hline
\end{tabular}

Table 3. Pearson correlation coefficient analysis of selected environmental variables used in the final model

\begin{tabular}{c|c|c|c|c|c|c}
\hline Variable & bio1 & bio2 & bio4 & bio5 & bio15 & bio18 \\
\hline bio1 & & & & & & \\
bio2 & -0.572 & & & & & \\
bio4 & -0.522 & 0.201 & & & & \\
bio5 & 0.625 & -0.404 & 0.323 & & & \\
bio15 & -0.449 & 0.742 & 0.154 & -0.380 & & \\
bio18 & 0.609 & -0.370 & -0.667 & 0.030 & -0.211 & \\
bio19 & 0.565 & -0.687 & -0.132 & 0.504 & -0.782 & 0.378 \\
\hline
\end{tabular}

\section{Modeling performance}

The MaxEnt model can directly draw ROC curves and calculate the AUC value of the model, which can be then used for result validation. The ROC curves of the initial model and the reconstruction model under present climatic conditions are displayed in Figure 2. The AUC values for the training data and the test data of the initial model were 0.98 and 0.975 , respectively, and the average AUC value of 10 replicates of the reconstruction model was 0.977 (Figure 2). Figure 3 shows the AUC values under future climatic conditions. Curve analysis revealed that the average AUC values of the training data were all higher than 0.978, which was much greater than the AUC value of the random simulation model (0.5), suggesting that the accuracy of the prediction results was "excellent". These results demonstrate that the model can be used for the potential habitat suitability of $S$. frugiperda in China. 

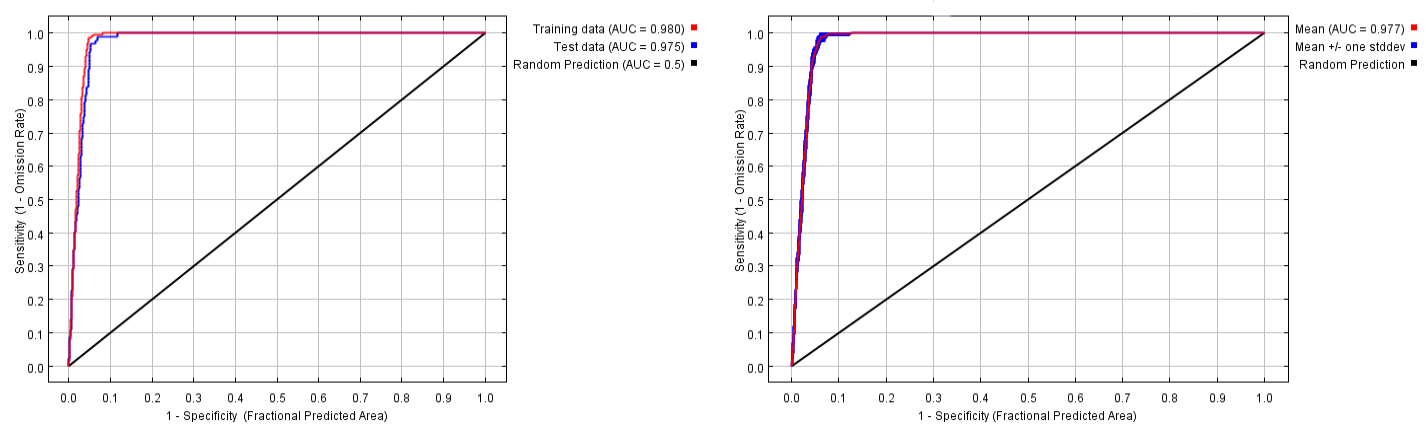

Figure 2. ROC curve and AUC values for the initial model and the reconstructed model under current climatic conditions

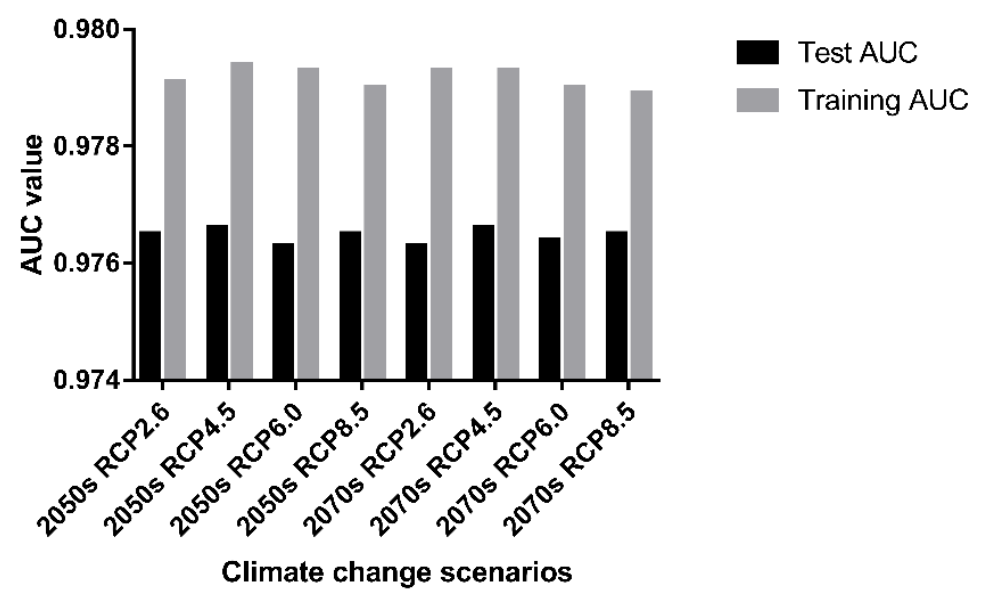

Figure 3. ROC curves and AUC values of the final model for future scenarios

\section{Modeled current potential distribution}

A graphical representation of the present potential distribution of S. frugiperda based on collected occurrence data and environmental variables modeled by the MaxEnt software was created using ArcGIS v10.7 software and is shown in Figure 4. The simulation results of the MaxEnt model suggested that the range of suitable habitats of S. frugiperda in China was very wide, and that unsuitable regions were mainly located in Qinghai-Tibet Plateau, Xinjiang, Jilin, Inner Mongolia, eastern Heilongjiang, and western Gansu. The highly suitable areas for $S$. frugiperda in China were mainly distributed in Jiangsu, Anhui, Jiangxi, most parts of Henan and Guangxi, central and eastern Hubei, central and southern Shaanxi, southeastern and northern Zhejiang, western Shandong, southern Hebei, northeastern Guizhou, eastern Sichuan, northwestern Hunan, western Chongqing, southeastern Fujian and northern Guangdong, spanning an area of $167.01 \times 10^{4} \mathrm{~km}^{2}$. The moderately suitable areas were mainly concentrated in most parts of Fujian, western and eastern Guangdong, central and northern Yunnan, central and eastern Shandong, central and southeastern Beijing, western Guizhou, northern Hainan, southeastern Hunan, western Hubei, western Hebei, northern Taiwan, and sporadic areas of Zhejiang, spanning an area of $124.13 \times 10^{4} \mathrm{~km}^{2}$. The total highly suitable, moderately suitable, marginally suitable and unsuitable areas comprised $17.6 \%, 13.08 \%, 8.88 \%$ and $60.43 \%$, respectively, of the total Chinese landmass. 


$$
-4535-
$$

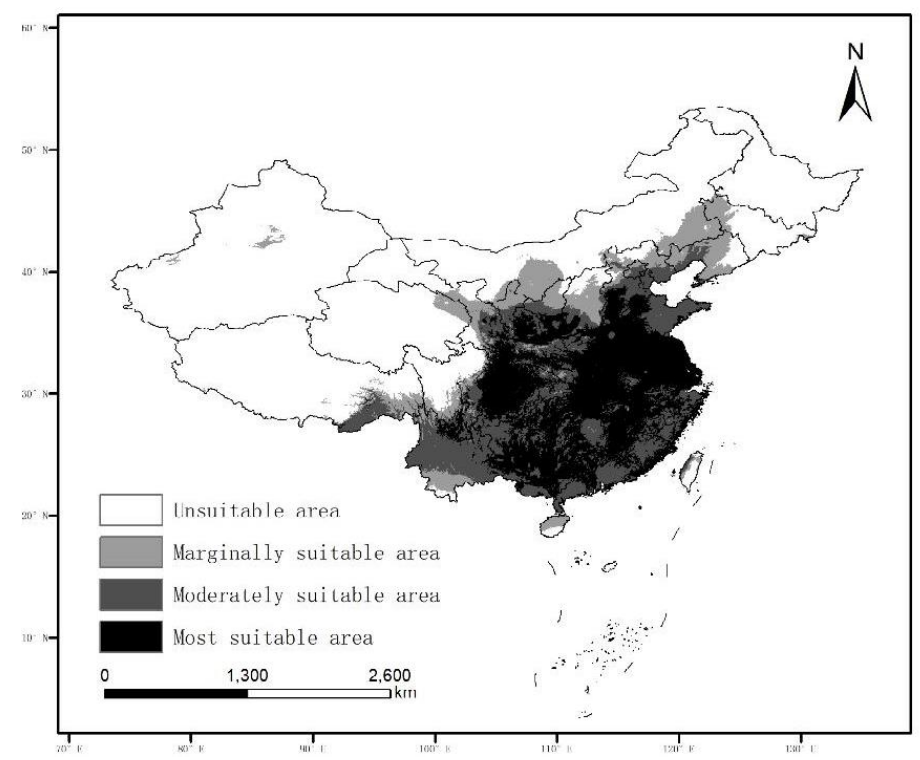

Figure 4. Probability of the current potential distribution of S. frugiperda in China

Response curves display the quantitative relationship between a bioclimatic variable and the logistic habitat suitability, helping us to better understand the ecological niche of a species. Responses curves for the effect of 7 bioclimatic variables on $S$. frugiperda are shown in Figure 5. Based on this analysis, the most contributing variable to high suitability was a precipitation of $386.41-923.07 \mathrm{~mm}$ for bio18. Other climate conditions also displayed a relationship with high probability of presence, namely 7321.84-9928.73 for bio4, $12.04-18.54{ }^{\circ} \mathrm{C}$ for bio1 and 53.08-92.65 for bio15. The results suggested that the maximum habitat suitability of $S$. frugiperda occurred when Precipitation of Warmest Quarter was $544.93 \mathrm{~mm}$, Temperature Seasonality (standard deviation $\times 100$ ) was 9064.27, Annual Mean Temperature was $15.26{ }^{\circ} \mathrm{C}$, Precipitation Seasonality (Coefficient of Variation) was 81.39, Mean Diurnal Range was $7.34{ }^{\circ} \mathrm{C}$, Precipitation of Coldest Quarter was $189.5 \mathrm{~mm}$ and Max Temperature of Warmest Month was $32.48^{\circ} \mathrm{C}$.

\section{Potential future distribution under different climatic conditions}

The predicted distribution of $S$. frugiperda under four representative climate change scenarios for future intervals 2050s and 2070s are illustrated in Figure 6 and Table 4. The results showed significant differences between the current suitable habitat and those predicted for future periods, with the risk-free area narrowing and risk area expanding continuously.

In the 2050s interval, the area of habitat unsuitable for S. frugiperda under RCP2.6, RCP4.5, RCP6.0 and RCP8.0 scenarios would reduce by $4.27 \%, 6.07 \%, 6.07 \%$ and $9.32 \%$, respectively, whereas the marginally suitable area would increase by $17.54 \%$, $12.60 \%, 6.88 \%$ and $12.06 \%$. Moreover, the highly suitable habitats would decrease under RCP2.6 and RCP 4.5 by $7.44 \%$ and $1.55 \%$, respectively, but increase by $22.08 \%$ and $12.82 \%$ under RCP6.0 and RCP8.5. Except for the scenario of RCP 6.0, the moderately suitable area of $S$. frugiperda under would increase under the other scenarios, RCP2.6, RCP4.5 and RCP8.0, by $17.85 \%, 21.55 \%$ and $17.60 \%$, respectively (Table 4). 


$$
-4536-
$$
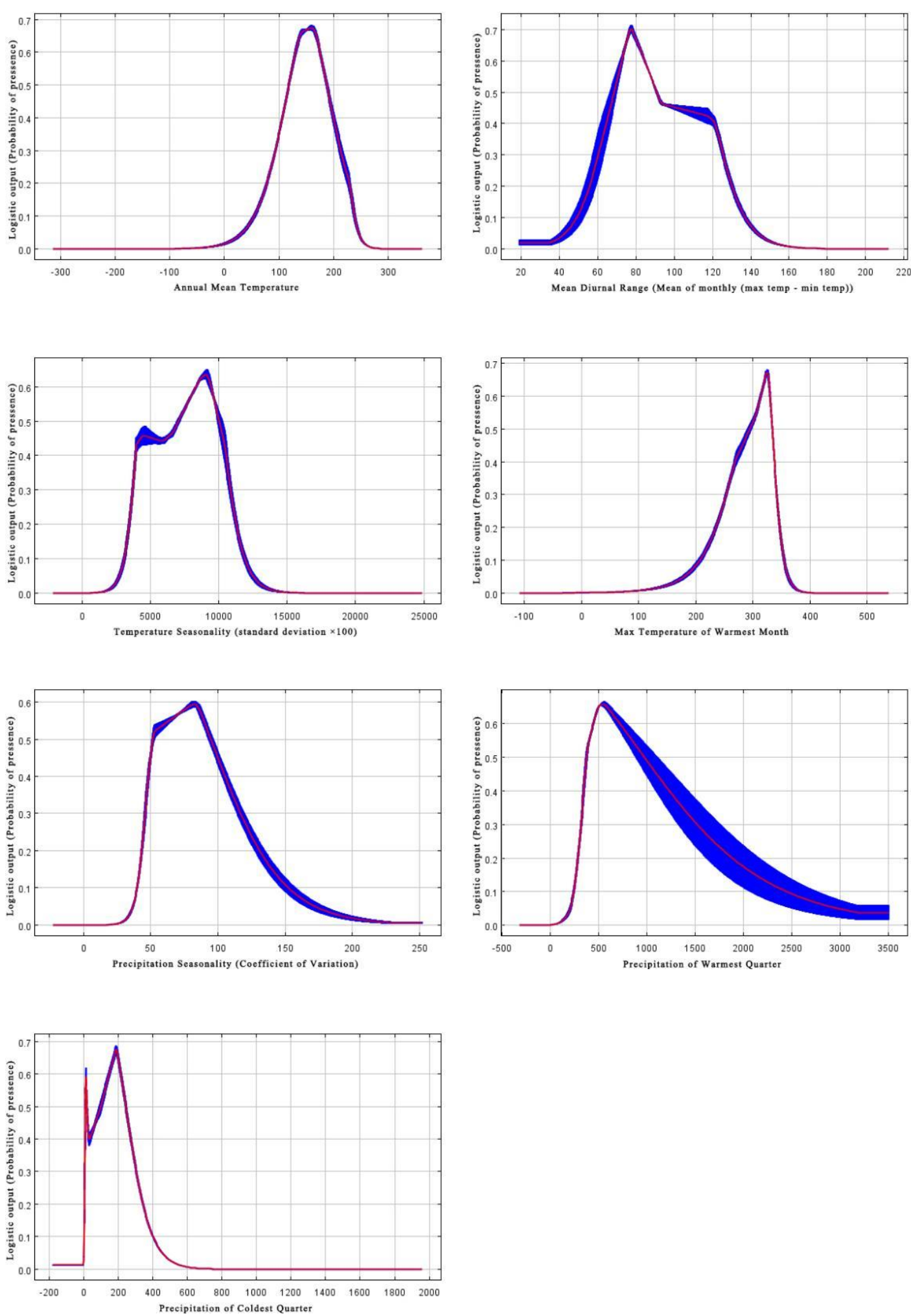

Figure 5. Response curves of 7 environmental variables showing their relationship with the habitat suitability of $S$. frugiperda. The red line indicates the mean response and the blue areas are $\pm S D$ calculated over 10 replicates 


$$
-4537 \text { - }
$$
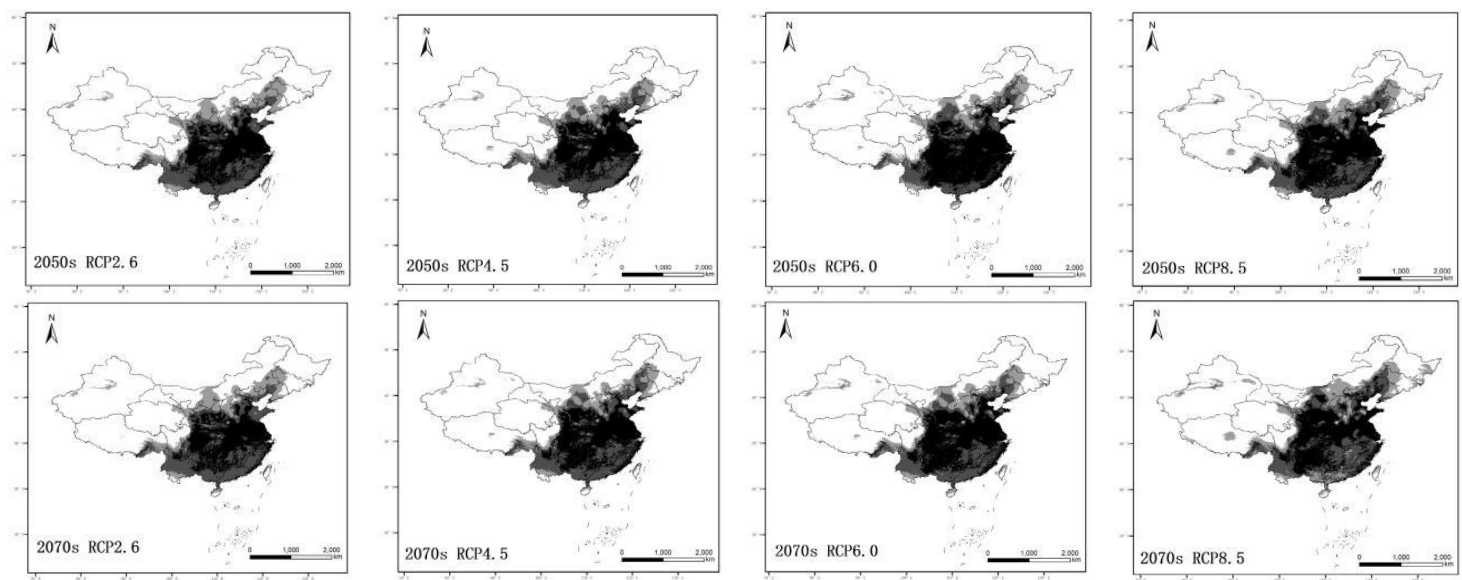

Figure 6. Potential habitat suitability of S. frugiperda under different climate change scenarios.

The white, light gray, dark gray, and black shading represent the unsuitable, marginally suitable, moderately suitable, and highly suitable areas, respectively

Table 4. Predicted suitable habitats for S. frugiperda under current and future climatic situations

\begin{tabular}{c|c|c|c|c|c|c|c|c|c}
\hline \multicolumn{2}{l|}{} & \multicolumn{4}{c|}{ Predicted area $\left(\times \mathbf{1 0}^{\mathbf{4}} \mathbf{k m}^{\mathbf{2}}\right)$} & \multicolumn{3}{c}{ Comparison with current distribution (\%) } \\
\hline \multirow{2}{*}{ Period } & Scenario & $\begin{array}{c}\text { Unsuitable } \\
\text { area }\end{array}$ & $\begin{array}{c}\text { Marginally } \\
\text { suitable } \\
\text { area }\end{array}$ & $\begin{array}{c}\text { Moderately } \\
\text { suitable } \\
\text { area }\end{array}$ & $\begin{array}{c}\text { Highly } \\
\text { suitable } \\
\text { area }\end{array}$ & $\begin{array}{c}\text { Unsuitable } \\
\text { area }\end{array}$ & $\begin{array}{c}\text { Marginally } \\
\text { suitable } \\
\text { area }\end{array}$ & $\begin{array}{c}\text { Moderately } \\
\text { suitable } \\
\text { area }\end{array}$ & $\begin{array}{c}\text { Highly } \\
\text { suitable } \\
\text { area }\end{array}$ \\
\hline Current & - & 573.4 & 84.26 & 124.13 & 167.01 & - & - & - & - \\
\hline \multirow{3}{*}{$2050 s$} & RCP2.6 & 548.89 & 99.04 & 146.29 & 154.58 & -4.27 & 17.54 & 17.85 & -7.44 \\
& RCP4.5 & 538.62 & 94.88 & 150.88 & 164.42 & -6.07 & 12.60 & 21.55 & -1.55 \\
& RCP6.0 & 538.6 & 90.06 & 116.26 & 203.88 & -6.07 & 6.88 & -6.34 & 22.08 \\
& RCP8.5 & 519.98 & 94.42 & 145.98 & 188.42 & -9.32 & 12.06 & 17.60 & 12.82 \\
\hline \multirow{3}{*}{$2070 \mathrm{~s}$} & RCP2.6 & 551.13 & 100.71 & 147.77 & 149.18 & -3.88 & 19.52 & 19.04 & -10.68 \\
& RCP4.5 & 492.9 & 119.46 & 159.37 & 177.05 & -5.15 & 7.90 & 13.64 & 3.55 \\
& RCP6.0 & 529.78 & 96.75 & 134.41 & 187.85 & -7.61 & 14.82 & 8.28 & 12.48 \\
& RCP8.5 & 492.91 & 119.46 & 159.37 & 177.05 & -14.04 & 41.78 & 28.39 & 6.01 \\
\hline
\end{tabular}

Abbreviations: -, not applicable

In the 2070s, the area of unsuitable habitats would reduce for all scenarios (RCP2.6, RCP4.5, RCP6.0 and RCP8.0) by 3.88\%, 5.15\%, 7.61\% and 14.04\%, respectively, while the areas of marginally suitable and moderately suitable habitats would increase by different amounts (Table 4). Regarding highly suitable habitats, scenario RCP2.6 resulted in the area reducing by $10.68 \%$, but it would increase for RCP4.5, RCP6.0 and RCP8.5 by $6.01 \%, 12.48 \%$ and $6.01 \%$, respectively.

\section{The transposition pathway of the geometric center of $S$. frugiperda under future scenarios}

To determine the effects of climate change on the habitat suitability of $S$. frugiperda, the spatial analysis function of AcrGIS was used to calculate the position of the geometric 
center, migration distance and direction of $S$. frugiperda under different climatic scenarios in China. The results are shown in Figure 7 and elaborated below.
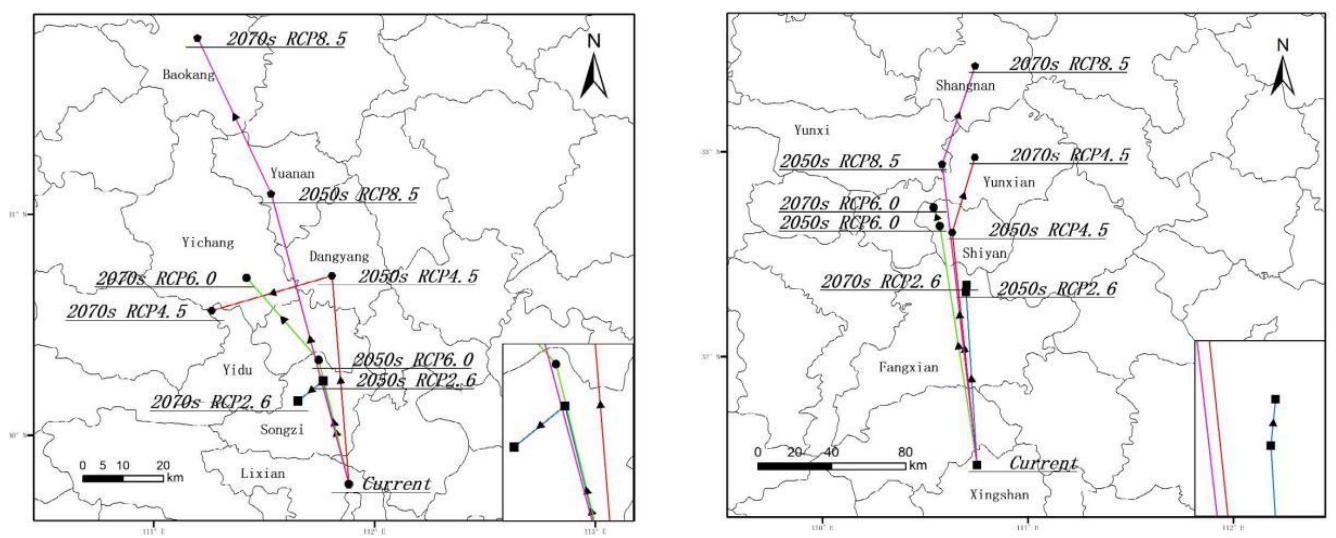

Figure 7. Trajectory of the geometric center of highly suitable (A) and total suitable (B) areas under different climate change scenarios. "•”, “曰" and " " indicate the geometric center of suitable areas under each scenario, and " $\boldsymbol{\Delta}$ " indicates the direction of movement

Under RCP2.6, the geometric center of highly suitable habitat for S. frugiperda will transpose $53.199 \mathrm{~km}$ northwest from Lixian (current) to Songzi (2050s), then $14.865 \mathrm{~km}$ southwest in Songzi (2070s). For the total suitable areas, the geometric center will move $94.068 \mathrm{~km}$ northwest from Xingshan (current) to Fangxian (2050s), then $3.711 \mathrm{~km}$ northeast in Fangxian (2070s).

Under RCP4.5, the geometric center of the highly suitable areas will move $105.068 \mathrm{~km}$ northwest from Lixian (current) to Dangyang (2050s), then $54.969 \mathrm{~km}$ southwest to Yidu (2070s). For total suitable areas, the center will transfer $126.547 \mathrm{~km}$ northwest from Xingshan (current) to Shiyan (2050s), then $41.907 \mathrm{~km}$ northeast to Yunxian (2070s).

Under RCP6.5, the geometric center of the highly suitable areas will move $63.67 \mathrm{~km}$ northwest from Lixian (current) to Songzi (2050s), then $51.899 \mathrm{~km}$ northwest to Yichang (2070s). For total suitable areas, center will move $130.762 \mathrm{~km}$ northwest from Xingshan (current) to Shiyan (2050s), then $10.422 \mathrm{~km}$ northwest in Shiyan (2070s).

Under RCP8.5, the geometric center of the highly suitable areas will move 149.944 $\mathrm{km}$ northwest from Lixian (current) to Yuanan (2050s), then $84.65 \mathrm{~km}$ northwest to Baokang (2070s). For total suitable areas, the center will move $164.008 \mathrm{~km}$ northwest from Xingshan (current) to Yunxi (2050s), then $53.315 \mathrm{~km}$ northeast to Shangnan (2070s).

\section{Discussion}

Spodoptera frugiperda is an important transboundary migratory insect pest, which has expanded its range to new areas, including China, forcing the Food and Agriculture Organization of the United Nations to issue alerts worldwide. The strain that has recently invaded China is considered the "maize strain" with some heterozygotes and at present threatens more than $50 \%$ of the maize crop producing areas in China, leading to huge economic loss and potentially influencing food security (da Silva et al., 2017; Huang et al., 2020). Recently, the Chinese government has launched the "three areas, three belts, and three lines of defense" policies to deal with this notorious pest. With the ever- 
increasing impact of climate change and its related consequences, a raised incidence of reduced agricultural production and food insecurity are expected, particularly since climate change will negatively affect the agricultural suitability of some areas, enhance the risk of pest infestation, and even alter the distribution of some crops (Kukal and Irmak, 2018; Deutsch et al., 2018). Within this context, assessing the impact of climate change on agricultural production systems will help to mitigate its negative consequences.

From the viewpoint of niche conservation, high accuracy in predicting the geographical distribution of a species can be achieved using local occurrence data for a particular species (Phillips, 2007). However, accurately modeling its simulation results for other areas and predicting the probability of presence in this area is usually unstable. It is not recommended to use occurrence data from one region to project habitat suitability in another; therefore, for the present research, we used data relating solely to $S$. frugiperda in China.

In the present study, we used a MaxEnt model combined with ArcGIS to understand the effects of climate change on areas potentially suitable for $S$. frugiperda at a national level. Furthermore, we investigated how these changes could influence the geometric center of this pest at two different time points, the 2050s and 2070s, and under four different climate change scenarios. ROC curves were applied to estimate the accuracy of the prediction of the MaxEnt model; the results showed high AUC values, confirming excellent model performance. Seven bioclimatic variables were then selected as predictors in the reconstructed MaxEnt model. bio18 (Precipitation of Warmest Quarter) was found to have the strongest effect on the potential distribution of this pest and contributed more to the simulation than other variables (Table 2). Notably, the impact of precipitation on habitat suitability for $S$. frugiperda has already been documented. For instance, Du Plessis et al. (2018) mapped the habitat suitability of this pest and suggested that precipitation and irrigation scenarios were important factors in the distribution of $S$. frugiperda. Moreover, Day et al. (2017) reported that precipitation in the wettest month and the mean temperature of coldest quarter were important variables in the diffusion of this pest in Africa. Rainfall can directly and indirectly influence the distribution of $S$. frugiperda, with both positive and negative consequences. That is, precipitation can contribute to the proliferation of host plants, an important habitat and food resource, thereby generating favorable conditions for the $S$. frugiperda population; meanwhile, precipitation and irrigation can drown or wash them away, reducing their population (Nboyine et al., 2020). Additionally, Early et al. (2018) found that precipitation had a negative influence on the larvae of $S$. frugiperda, with fewer adult moths captured and the peaks of moth population were postponed during the dry season (Andrews, 1988).

Previous studies have also shown temperature to be a key environmental variable, influencing the development, reproduction and distribution of S. frugiperda (Hogg et al., 1982). Valdez-Torres et al. (2012) reported that the highest and lowest temperature thresholds for the growth of $S$. frugiperda under laboratory conditions were 39.8 and $8.7^{\circ} \mathrm{C}$, respectively. In the present study, the existence probability of $S$. frugiperda was found to be higher when the mean annual temperature (bio1) was between 12.0 and $18.5{ }^{\circ} \mathrm{C}$, which is within the aforementioned temperature range. However, it is inconsistent with another previous study which suggested that the suitable mean annual temperature ranged from 19 to $23{ }^{\circ} \mathrm{C}$ (Wang et al., 2020). This difference is likely due to the difference in geographical location of the sample points and environmental factors in establishing the prediction model. In South and East China, which are considered highly and moderately suitable areas for $S$. frugiperda, the annual average temperature was about 
15-18 ${ }^{\circ} \mathrm{C}$ (data from China Meteorological Administration), characterized by higher winter temperatures and a short duration of low temperature, which are good climatic conditions for the persistence of this pest. Hence, it was inferred that this pest could reproduce all year round in these areas and thus it may become the central location from which S. frugiperda can spread to other parts of China, such as the Yangtze River Basin and North China. Within a certain temperature range, the development rate of insects has been found to increase with increasing climatic temperature but reduces beyond a certain threshold (Wang et al., 2020). Similarly, a previous study indicated that the growth rate of $S$. frugiperda increases linearly with increasing temperature between the range of $18-30{ }^{\circ} \mathrm{C}$ (Du Plessis et al., 2018). Furthermore, based on the response curve of bio5, the occurrence probability of $S$. frugiperda reduced sharply when temperatures exceeded $32.5^{\circ} \mathrm{C}$, indicating that a high temperature in the warmest quarter may be an important factor restricting the habitat suitability of this pest.

In summary, the occurrence and prevalence of S. frugiperda are closely associated with climatic conditions, such as temperature and rainfall (Ramirez-Cabral et al., 2017). This is supported by research in Africa by Cokola et al. (2020), who found that the incidence of $S$. frugiperda in South Kivu Province, DC Congo was also related to temperature and rainfall. However, the habitat suitability of $S$. frugiperda may be affected by other non-climatic factors, such as host plants, natural enemies, human activities, land use, soil traits and management intervention levels (Hijmans et al., 2005; BiberFreudenberger et al., 2016). In a paper by Liu et al. (2020), the authors noted that landuse was more important than climate in regulating the distribution of S. frugiperda, according to the resource concentration hypothesis (Root, 1973). Whether these factors can exert a significant effect on the accuracy of our simulation results deserves to be investigated.

The results of the present study highlight the potential for climate change to increase the spread of pests. As conditions become more favorable for pest species, their ability to expand and damage crops grows, as elaborated by examples worldwide (Deutsch et al., 2018). Our future simulations were performed under four different $\mathrm{CO}_{2}$ concentration pathways, whereby RCP2.6 represents the most optimistic scenario, RCP8.5 represents the most pessimistic, and RCP4.5 and RCP6.0 in between (IPCC, 2007). Our study confirmed that the total area of suitable habitats increased in line with the severity of greenhouse gases emissions (to different extents). This, therefore, indicates that climate change could extend the potential distribution of $S$. frugiperda, which is consistent with previous studies (Early et al., 2018). The alteration in habitat suitability caused by climate change could be explained by the biological traits of insects. Since they are temperaturesensitive, and have a strong spread ability, short life-cycles, and strong reproductive capacity, even slight alterations in temperature have the potential to bring about significant changes in abundance and distribution (Ayres and Lombardero, 2000). However, climate change has also been documented to have other impacts on insects, such as directly influencing their life history traits or indirectly through their natural enemies and hosts plants (Patterson et al., 1999; Bale et al., 2002), resulting in changes to the suitability of a particular insect for a given habitat. Ramirez-Cabral et al. (2017) has suggested that the low-risk area would increase $40 \%$ by 2050 and $23 \%$ by 2100 but medium- and high-risk areas would in fact reduce more than $50 \%$ by 2050 and more than $39 \%$ by 2100 , compared with the present risk. As such, they concluded that that fure climate scenarios (A2 Special Report on Emissions Scenarios, SRES) would result in a reduction of risk for $S$. frugiperda outbreaks (Ramirez-Cabral et al., 2017). However, 
unlike in the present study, the authors used two general circulation models (GCM) including CRIRO MK3.0 and MIROC-H under the scenario of A2 SRES.

Additionally, the results of the present study highlighted that $S$. frugiperda is highly likely to migrate northward in China. The geometric center of both highly and total suitable areas was found to move northwards under all four climate scenarios. This can be clearly explained by the fact that polyphagous insects, such as $S$. frugiperda, are able to transfer to more favorable areas as conditions change (Kennedy and Storer, 2000). Therefore, rapid cross-region communication and collaboration in China will be key to effective management, especially in regions that are climatically low- or unsuitable for $S$. frugiperda. At present, $S$. frugiperda is a seasonal pest in most parts of China, and the warmer weather may enable this pest to persevere over a longer period, as highlighted by the future simulations (Xie et al., 2021). Furthermore, S. frugiperda may benefit from climate change since polyphagous insects are more adaptable to a changing environment due to their genotypic and phenotypic plasticity, and may even feed on lower-quality hosts when preferred hosts are unavailable (Bale et al., 2002). Moreover, climate change may accelerate the northward migration of multivoltine insects to higher and medium latitudes (Altermatt, 2010). Thus, those areas currently designated as either low- or unsuitable may ultimately become suitable for $S$. frugiperda. From another point of view, pest outbreaks and their risks, under future climate situations, may be more difficult to model due to enhanced climate variability and extreme climate events. Of note, the strong flight ability of adult $S$. frugiperda is yet another of their adaptative characteristics that enables them to translocate long distances (29.14 km/day in China, Ge et al., 2019), a key factor that has promoted the expansion of this pest. However, its ability in long-distance migration is only partly to blame and research has indicated that the movement of infested agricultural commodities also promoted its migration between regions (Wang et al., 2020). For example, Faulkner et al. (2017) speculated that the rapid diffusion of this pest throughout Africa was aided by intra-continental transportation links. Within China, this feature may make it more challenging to suppress outbreaks of $S$. frugiperda by managing any single location. Therefore, efforts need to be coordinated across areas and country borders.

The host plants of $S$. frugiperda are diverse, with major hosts extensively distributed around the world. Thus, the host plant may not be a significant factor in restricting their distribution. Currently, $S$. frugiperda can be divided into two haplotypes, namely maize strain and rice strain. Rice-strain $S$. frugiperda feed on rice and various pastures, whilst the maize-strain (which recently invaded China) feeds mainly on maize, sorghum and cotton (Dumas et al., 2015). In China, maize is one of the major grain crops, and is widely cultivated and distributed in the hilly maize area of South and Southwest China, irrigation maize area of Northwest China, spring maize area of East and North China, summer maize area of Huanghuaihai Plain, and maize area of Qinghai-Tibet Plateau (He and Zhou, 2011, 2012), with several of these production areas overlapping with the moderately and highly suitable areas for $S$. frugiperda in our results. At present, there has been little study into the differing climate tolerances between rice- and maize-strain S. frugiperda and there is insufficient information on their respective habitat suitability to model their distribution individually. At present, the two strains appear to substantially overlap in their distributions, thus we inferred that any difference in climate tolerance was unlikely to exert a significant influence on their geographic distribution, but has the potential affect their abundance. As such, further research is needed. According to previous records, no $S$. frugiperda have been detected in Qinghai-Tibet Plateau, Xinjiang, 
Jilin, Heilongjiang or Gansu, which were identified as unsuitable areas for the pest. However, this does not imply that these areas will not be severely affected and can be ignored, given the ability of $S$. frugiperda to migrate long distances.

Finally, it is important to acknowledge some constraints with the present research. First, we only used climatic factors and did not investigate the effect of other biotic or abiotic factors which could significantly affect species distribution, such as host plant, natural enemies, land use or the application of pesticide and fertilizer, etc. Secondly, MaxEnt, as an occurrence-background approach, cannot adequately illustrate the spatial deviation of presence records (Shabani et al., 2019), and only evaluates the relative habitat suitability irrespective of how the background sample is specified (Guillera-Arroita et al., 2014).

\section{Conclusion}

Native to the Americas, S. frugiperda is one of the most economically destructive crop pests that has recently invaded both Asia and Africa. In general, pest management within agricultural systems may become more difficult under future climate change scenarios, particularly in terms of its variability. Understanding the effect of climate change on the habitat of this pest and responding with timely management measures are therefore essential to protect future crop production. The results of the present study show that the high-risk area is mainly distributed in Jiangsu, Anhui, Jiangxi, most parts of Henan and Guangxi, central and eastern Hubei, central and southern Shaanxi, southeastern and northern Zhejiang, western Shandong, southern Hebei, northeastern Guizhou, eastern Sichuan, northwestern Hunan, western Chongqing, southeastern Fujian and northern Guangdong, covering a total area of $167.01 \times 10^{4} \mathrm{~km}^{2}$. From the present to the $2070 \mathrm{~s}$, the area of highly and moderately suitable areas will increase, with the distribution expanding toward northern China as the climate warms. The ROC curve test performed in the present study offers reliable evidence that the MaxEnt model is highly accurate in predicting the potential distribution of $S$. frugiperda in China. Moreover, the key environmental factors regulating the habitat suitability of this pest were Precipitation of Warmest Quarter, Temperature Seasonality, Annual Mean Temperature and Precipitation Seasonality.

As a next step, we recommend the use of ensembles of ecological niche models such as MaxEnt, Climex, BIOCLIM and GARP to estimate the future habitat suitability of $S$. frugiperda, its host plants and natural enemies in China, and integrate their interaction into the model simulation process. With this information, crop growers, the agricultural sector and policy makers could develop adaptation strategies, such as new techniques, new pest-resistant crop varieties and control practices, to overcome the climate changeinduced effects of $S$. frugiperda on economically important crops. Further work is needed at a regional level to understand the factors affecting the development and life history traits of this pest.

Acknowledgements. This research was financially supported by Innovation and Entrepreneurship Training Program for College Students of Fujian Province (202110397033), Advanced Talents Introduction Project of Wuyi University (YJ201910), Education and Scientific Research Project for Young and Middle-aged Teachers in Fujian Province (JAT190801, JAT190805), Science \& Technology Innovation Platform Construction Project of Fujian Province (2018N2004) and Scientific Research Team Jointly Build By Teachers and Students of Wuyi University (20200701-20230630). 


$$
-4543 \text { - }
$$

Author Contributions. PC, FM: conceived and designed the experiments. YS, YP, QW, SL: collected the sample data. FM, YS, YP, QW, SL, CM, YH, DH and LL: performed the experiments. FM: carried out the data analysis. PC: drafted the manuscript.

Conflict of interests. The authors declare that they have no competing interests.

\section{REFERENCES}

[1] Altermatt, F. (2010): Climatic warming increases voltinism in European butterflies and moths. - Proceedings of the Royal Society B: Biological Sciences 277: 1281-1287.

[2] Andrews, K. L. (1988): Latin American research on Spodoptera frugiperda (Lepidoptera: Noctuidae). - Florida Entomologist 71: 630-653.

[3] Araujo, M. B., Pearson, R. G., Thuiller, W., Erhard, M. (2005): Validation of speciesclimate impact models under climate change. - Global Change Biology 11: 1504-1513.

[4] Ayres, M. P., Lombardero, M. J. (2000): Assessing the consequences of global change for forest disturbance from herbivores and pathogens. - Science of the Total Environment 262: 263-286.

[5] Bale, J. S., Masters, G. J., Hodkinson, I. D., Awmack, C., Bezemer, T. M., Brown, V. K., Butterfield, J., Buse, A., Coulson, J. C., Farrar, J., Good, J. E. G., Harrington, R., Hartley, S., Jones, T. H., Lindroth, R. L., Press, M. C., Symrnioudis, I., Watt, A. D., Whittaker, J. B. (2002): Herbivory in global climate change research: direct effects of rising temperature on insect herbivores. - Global Change Biology 8: 1-16.

[6] Baloch, M. N., Fan, J., Haseeb, M., Zhang, R. (2020): Mapping potential distribution of Spodoptera frugiperda (Lepidoptera: Noctuidae) in central Asia. - Insects 11(11): 1-10.

[7] Battisti, A., Stastny, M., Netherer, S., Robinet, C., Schopf, A., Roques, A., Larsson, S. (2005): Expansion of geographic range in the pine processionary moth caused by increased winter temperatures. - Journal of Applied Ecology 15: 2084-2096.

[8] Biber-Freudenberger, L., Ziemacki, J., Tonnang, H. E. Z., Borgemeister, C. (2016): Future risks of pest species under changing climatic conditions. - PLoS ONE 11(4): e0153237.

[9] Brito, J. C., Acosta, A. L., Alvares, F., Cuzin, F. (2009): Biogeography and conservation of taxa from remote regions: an application of ecological-niche based models and GIS to North-African Canids. - Biological Conservation 142: 3020-3029.

[10] Celine, B., Cleo, B., Paul, L., Wilfried, T., Franck, C. (2012): Impacts of climate change on the future of biodiversity. - Ecology Letters 15(4): 365-377.

[11] Center for Agriculture and Bioscience International. Datasheet. Spodoptera frugiperda (fall armyworm). (2016): Invasive Species Compendium. - Available online: http://www.cabi.orglisc/datasheet129810 (accessed on 5 June 2020).

[12] Cokola, M. C., Yannick, M., Noel, G., Espoir, B., David, B., Chuma, G., Adrien, B., Francis, F. (2020): Bioclimatic zonation and potential distribution of Spodoptera frugiperda (Lepidoptera: Noctuidae) in South Kivu Province, DR Congo. - BMC Ecology 20(66): 1-13.

[13] Da Silva, D. M., de Freitas Bueno, A., Andrade, K., dos Santos Stecca, C., Neves, P. M. O. J., de Oliveira, M. C. N. (2017): Biology and nutrition of Spodoptera frugiperda (Lepidoptera: Noctuidae) fed on different food sources. - Scientia Agricola 74: 18-31.

[14] Day, R., Abrahams, P., Bateman, M., Beale, T., Clottey, V., Cock, M., Colmenarez, Y., Corniani, N., Early, R., Godwin, J., Gomez, J., González-Moreno, P., Murphy, S. T., Oppong-Mensah, B., Phiri, N., Pratt, C., Silvestri, S., Witt, A. (2017): Fall Armyworm: impacts and implications for Africa. - Outlook Pest Management 28: 196-201.

[15] Deutsch, C. A., Tewksbury, J. J., Tigchelaar, M., Battisti, D. S., Merrill, S. C., Huey, R. B., Naylor R. L. (2018): Increase in crop losses to insect pests in a warming climate. Science 361(6405): 916-919. 
[16] Dong, S. Y., Gao, X. J. (2014): Long-term climate change: interpretation of IPCC fifth assessment report. - Progressus Inquisitiones de Mutatione Climatis 10: 56-59.

[17] Du Plessis, H., Van den Berg, J., Ota, N., Kriticos, D. J. (2018): Spodoptera frugiperda. CSIRO - InSTePP Pest Geog: 1-7.

[18] Dumas, P., Legeai, F., Lemaitre, C., Scaon, E., Orsucci, M., Labadie, K., Gimenez, S., Clamens, A. L., Henri, H., Vavre, F., Aury, J. M., Fournier, P., Kergoat, G. J., d'Alençon, E. (2015): Spodoptera frugiperda (Lepidoptera: Noctuidae) host-plant variants: two host strains or two distinct species? - Genetica 143(3): 305-316.

[19] Early, R., González-Moreno, P., Murphy, S. T., Day, R. (2018): Forecasting the global extent of invasion of the cereal pest Spodoptera frugiperda, the fall armyworm. - NeoBiota 40: 25-50.

[20] Ekesi, S., Meyer, M. D., Mohamed, S. A., Virgilio, M., Borgemeister, C. (2016): Taxonomy, ecology, and management of native and exotic fruit fly species in Africa. Annual Review of Entomology 61(1): 219-238.

[21] Elith, J., Graham, C. H., Anderson, R. P., Dudík, M., Ferrier, S., Guisan, A., Hijmans, R. J., Huettmann, F., Leathwick, J. R., Lehmann, A. (2006): Novel methods improve prediction of species' distributions from occurrence data. - Ecography 29: 129-151.

[22] Faccoli, M. (2009): Effect of weather on Ipstypographus (Coleoptera: Curculionidae) phenology, voltinism, and associated spruce mortality in the southeastern Alps. Environment Entomology 38: 307-316.

[23] Fan, J., Wu, P., Tian, T., Ren, Q., Zhang, R. (2020): Potential distribution and niche differentiation of Spodoptera frugiperda in Africa. - Insects 11: 383.

[24] Fand, B. B., Kumar, M., Kamble, A. L. (2014): Predicting the potential geographic distribution of cotton mealybug Phenacoccus solenopsis (Hemiptera: Pseudococcidae) in India based on MAXENT ecological niche model. - Journal Environment Biology 35(5): 973-982.

[25] Faulkner, K. T., Hurley, B. P., Robertson, M. P., Rouget, M., Wilson, J. R. (2017): The balance of trade in alien species between South Africa and the rest of Africa. - Bothalia African Biodiversity \& Conservation 47(2): 1-16.

[26] Ge, S. S., He, L. M., He, W., Xu, R. B., Sun, X. T., Wu, K. M. (2019): Determination on moth flight capacity of Spodoptera frugiperda. - Plant Protection 45(4): 28-33.

[27] Guillera-Arroita, G., Lahoz-Monfort, J. J., Elith, J. (2014): Maxent is not a presenceabsence method: a comment on Thibaud et al. - Methods in Ecology \& Evolution 5(11): 1192-1197.

[28] He, Q. J., Zhou, G. S. (2011): Climatic suitability of potential summer maize planting zones in China. - Acta Geograph Sinica 66(11): 1443-1450.

[29] He, Q. J., Zhou, G. S. (2012): Climatic suitability of potential spring maize cultivation distribution in China. - Acta Ecologica Sinica 32(12): 3931-3939.

[30] Hijmans, R. J., Cameron, S. E., Parra, J. L., Jones, P. G., Jarvis, A. (2005): Very high resolution interpolated climate surfaces for global land areas. - International Journal of Climatology 25: 1965-78.

[31] Hogg, D. B., Pitre, H. N., Anderson, R. E. (1982): Assessment of early-season phenology of the fall armyworm (Lepidoptera: Noctuidae) in Mississippi. - Environment Entomology 11: 705-10.

[32] Huang, Y. R., Dong, Y. Y., Huang, W. J., Ren, B. Y., Deng, Q. Y., Shi, Y., Bai, J., Ren, Y., Geng, Y., Ma, H. Q. (2020): Overwintering distribution of fall armyworm (Spodoptera frugiperda) in Yunnan, China, and influencing environmental factors. - Insects 11(11): 805.

[33] IPCC (2007): Climate change 2007: the physical science basis. contribution of working group $i$ to the fourth assessment report of the intergovernmental panel on climate change. - Avaibale on http://www.ipcc.ch/publications_and_data/publications ipcc_fourth assessment_report_wg1_report_the_physical_science_basis.htm. 


$$
-4545-
$$

[34] Jiang, D., Chen, S., Hao, M. M., Fu, J. Y., Ding, F. Y. (2018): Mapping the potential global codling moth (Cydia pomonella L.) distribution based on a machine learning method. Scientifc Reports 8: 13093.

[35] Kennedy, G. G., Storer, N. P. (2000): Life systems of polyphagous arthropod pests in temporally unstable cropping systems. - Annual Review of Entomology 45: 467-493.

[36] Khanum, R., Mumtaz, A., Kumar, S. (2013): Predicting impacts of climate change on medicinal asclepiads of Pakistan using Maxent modeling. - Acta Oecologica 49: 23-31.

[37] Kukal, M. S., Irmak, S. (2018): Climate-driven crop yield and yield variability and climate change impacts on the U.S. Great Plains agricultural production. - Scientific Reports 8: 3450 .

[38] Kyrre, K., Bjorn, O., Olav, S., Jean, C. G., Nadir, E., Nils, C. S. (2012): Population dynamics in changing environments: the case of an eruptive forest pest species. Biological Reviews 87(1): 34-51.

[39] Li, G. Q., Liu, C. C., Liu, Y. G., Yang, J., Zhang, X. S., Guo, K. (2013): Advances in theoretical issues of species distribution models. - Acta Ecologica Sinica 33: 4827-4835.

[40] Li, Z. H., Qin, Y. J. (2018): Review on the quantitative assessment models for pest risk analysis and their comparison. - Plant Protection 44: 134-145.

[41] Liu, T., Wang, J., Hu, X., Feng, J. (2020): Land-use change drives present and future distributions of fall army worm, Spodoptera frugiperda (J. E. Smith) (Lepidoptera: Noctuidae). - The Science of Total Environment 706: 135872.

[42] Massin, M. B., Rome, Q., Muller, F., Perrard, A., Villemant, C., Jiguet, F. (2012): Climate change increases the risk of invasion by the yellow-legged hornet. - Biological Conservation 157: 4-10.

[43] Montezano, D. G., Specht, A., Sosa-Gomez, D. R., Roque-Specht, V. F., Sousa-Silva, J. C., Paula-Moraes, S. V., Peterson, J. A., Hunt, T. E. (2018): Host plants of Spodoptera frugiperda (Lepidoptera: Noctuidae) in the Americas. - African Entomology 26(2): $286 \mathrm{e} 301$.

[44] Nagoshi, R. N. (2019): Evidence that a major subpopulation of fall armyworm found in the Western Hemisphere is rare or absent in Africa, which may limit the range of crops at risk of infestation. - PLoS ONE 14: e0208966.

[45] National Agro-Tech Axtension and Service Center (2020): Occurrence trend of Spodoptera frugiperda in maize grassland on autumn. - https://www.natesc.org.cn/ (accessed on 3 September 2020).

[46] Nboyine, J. A., Kusi, F., Abudulai, M., Badii, B. K., Zakaria, M., Adu, G. B., Haruna, A., Seidu, A., Osei, V., Alhassan, S., Yahaya, A. (2020): A new pest, Spodoptera frugiperda (J.E. Smith), in tropical Africa: Its seasonal dynamics and damage in maize fields in northern Ghana. - Crop Protection 127: 104960.

[47] Patterson, D. T., Westbrook, J. K., Joyce, R. J. V., Lingren, P. D., Rogasik, J. (1999): Weeds, insects, and diseases. - Climatic Change 43: 711-27.

[48] Phillips, S. J. (2007): A Brief Tutorial on Maxent. - http://biodiversityinformatics.amnh. org/open_source/maxent/.

[49] Ramirez-Cabral, N. Y. Z., Kumar, L., Shabani, F. (2017): Future climate scenarios project a decrease in the risk of fall armyworm outbreaks. - The Journal of Agricultural 155(8): 1219-1238.

[50] Root, R. B. (1973): Organization of a plant-arthropod association in simple and diverse habitats: fauna of collards (Brassica oleracea). - Ecological Monographs 43: 95-120.

[51] Roy, H. E., De Clercq, P., Handley, L. J. L., Poland, R. L., Sloggett, J. J., Wajnberg, E. (2011): Alien arthropod predators and parasitoids: an ecological approach. - BioControl 56: 375-382.

[52] Shabani, F., Ahmadi, M., Peters, K. J., Haberle, S., Champreux, A., Saltre, F., Bradshaw, C. J. A. (2019): Climate-driven shifts in the distribution of koala-browse species from the Last Interglacial to the near future. - Ecography 42(9): 1587-1599. 


$$
-4546-
$$

[53] Simberloff, D., Martin, J. L., Genovesi, P., Maris, V., Wardle, D. A., Aronson, J., Courchamp, F., Galil, B., Garcia-Berthou, E., Pascal, M., Pysek, P., Sousa, R., Tabacchi, E., Vila, M. (2003): Impacts of biological invasions: what's what and the way forward. Trends in Ecology and Evolution 28: 58-66.

[54] Swets, J. A. (1988): Measuring the accuracy of diagnostic systems. - Science 240: 12851293.

[55] Tobin, P. C., Nagarkatti, S., Loeb, G., Saunders, M. C. (2008): Historical and projected interactions between climate change and insect voltinism in a multivoltine species. - Global Change Biology 14: 951-957.

[56] Valdez-Torres, J. B., Soto-Landeros, F., Osuna-Enciso, T., Baez-Sanudo, M. A. (2012): Phenological prediction models for white corn (Zea mays L.) and fall armyworm (Spodoptera frugiperda J.E. Smith). - Agrociencia 46(4): 399-410.

[57] Venette, R. C., Kriticos, D. J., Magarey, R. D., Koch, F. H., Baker, R. H. A., Worner, S. P., Raboteaux, N. N. G., McKenney, D. W., Dobesberger, E. J., Yemshanov, D., Barro, P. J. D., Hutchison, W. D., Fowler, G., Kalaris, T. M., Pedlar, J. (2010): Pest risk maps for invasive alien species: A roadmap for improvement. - Bioscience 60: 349-362.

[58] Wang, R. L., Li, Q., Feng, C. H., Shi, C. P. (2017): Predicting potential ecological distribution of Locusta migratoria tibetensis in China using maxent ecological niche modeling. - Acta Ecologica Sinica 37(24): 8556-8566.

[59] Wang, R. L., Li, Q., He, S. S., Liu, Y., Wang, M. T., Jiang, G. (2018): Modeling and mapping the current and future distribution of Pseudomonas syringae pv. actinidiae under climate change in China. - PloS ONE 13: e0192153.

[60] Wang, R. L., Yang, H., Luo, W., Wang, M. T., Lu, X. L., Huang, T. T., Li, Q. (2019): Predicting the potential distribution of the Asian citrus psyllid, Diaphorina citri (Kuwayama), in China using the MaxEnt model. - PeerJ 7: e7323.

[61] Wang, R., Jiang, C., Guo, X., Chen, D., You, C., Zhang, Y., Wang, M., Li, Q. (2020): Potential distribution of Spodoptera frugiperda (J. E. Smith) in China and the major factors influencing distribution. - Global Ecology Conservation 21: e00865.

[62] Wei, J., Zhang, H., Zhao, W., Zhao, Q. (2017): Niche shifts and the potential distribution of Phenacoccus solenopsis (Hemiptera: Pseudococcidae) under climate change. - PLoS ONE 12(7): e0180913.

[63] Xie, D. J., Tang, J. H., Zhang, L., Cheng, Y. X., Jiang, X. F. (2021): Annual generation numbers prediction and division of fall armyworm, Spodoptera frugiperda in China. Plant Protection 47(01): 61-67, 116.

[64] Xu, D. P., Wang, R. L., Ye, M., Pu, B. (2019): Modeling the distribution of Zanthoxylum armatum in China with MaxEnt modeling. - Global Ecology Conservation 19: e00691.

[65] Zacarias, D. A. (2020): Global bioclimatic suitability for the fall armyworm, Spodoptera frugiperda (Lepidoptera: Noctuidae), and potential co-occurrence with major host crops under climate change scenarios. - Climatic Change 161: 555-566.

[66] Zhang, Q., Zhao, L., He, P., Zheng, K. M., Wu, P. X., Fan, J. Y. (2020): The potential distribution analysis and economic loss assessment of Spodoptera frugiperda (Smith) in Qujing, Yunnan Province. - Journal of Yunnan University: Natural Sciences Edition 42(06): 1224-1229.

[67] Zhu, G. P., Liu, G. Q., Pu, W. J., Gao, B. Y. (2013): Ecological niche modeling and its applications in biodiversity conservation. - Biodiversity Science 21(1): 90-98. 